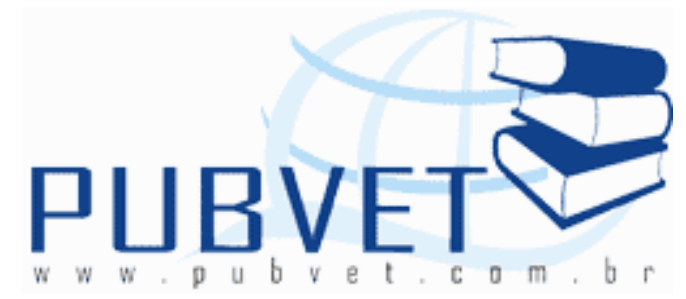

PUBVET, Publicações em Medicina Veterinária e Zootecnia.

\title{
Descarte responsável de embalagens de agrotóxico
}

Gabriela Marques de Oliveira ${ }^{1 *}$; Ludiêmilem Keith Parreira da Costa ${ }^{1}$; Paola Rezende Ribeiro ${ }^{1}$; Vanessa Thomaz de Freitas ${ }^{1}$; Natascha Almeida Marques da Silva ${ }^{2}$

${ }^{1}$ Discente do curso de Zootecnia, bolsista PET Zootecnia, Universidade Federal de Uberlândia.

2 Docente do curso de Zootecnia, tutora PET Zootecnia, Universidade Federal de Uberlândia

\section{Resumo}

Devido ao aumento da população mundial, houve necessidade da expansão da produção agrícola e, como consequência maior necessidade de uso de defensivos agrícolas. Contudo, essa utilização foi realizada de modo desordenado e sem controle, colocando em risco a saúde humana e dos animais, causando diretamente impactos no meio ambiente tais como contaminação dos solos, da água e do ar. Nesse contexto, foram criadas leis a fim de fiscalizar o uso de agrotóxicos e o descarte de embalagens desses produtos. Mediante essas leis, foram designadas responsabilidades a cada setor envolvido nesse processo: agricultores, comerciantes, fabricantes e poder público. Através de parcerias entre as indústrias e empresas privadas, foram desenvolvidos programas educativos e de conscientização que forneceram resultados positivos no Brasil, visto que há uma grande 
OLIVEIRA, G.M. et al. Descarte responsável de embalagens de agrotóxico. PUBVET, Londrina, V. 7, N. 8, Ed. 231, Art. 1527, Abril, 2013.

participação dos usuários e fornecedores de agrotóxicos, refletida no alto índice de destinação correta das embalagens. Sendo assim, objetivo do trabalho é conscientizar a população em geral sobre a importância do descarte correto das embalagens de agrotóxicos.

Palavras-chave: Defensivos agrícolas; Meio ambiente; INPEV; Destinação final correta; Legislação.

\title{
Proper disposal of pesticide containers
}

\begin{abstract}
Due to the growth of world population, there was a need for expansion of agricultural production and, therefore, an increase in pesticide use. However, such use was conducted in a disorderly way, endangering human and animal health and impacting the environment, such as soil, water and air contamination. In this context, it was created laws to supervise the use and disposal of pesticides containers. Responsibilities were assigned, by these laws, to each sector involved in the process: farmers, traders, manufacturers and government. It was desenvolved educational and awareness programs through partnerships between private companies and industries, providing positive results at Brazil, once the large participation of the sectors involved reflected in the high rate of correct disposal of the containers. This study aimed to educate the general population about the importance of proper disposal of pesticide containers.
\end{abstract}

Keywords: Pesticides; Environment; INPEV; Correct disposal; Legislation.

\section{INTRODUÇÃO}

Em um contexto geral, desde a antiguidade para defender as plantações, utilizavam-se substâncias químicas. Contudo, com o aumento da produtividade, causada pela crescente demanda de alimentos, houve necessidade de expansão do uso dessas substâncias, que atualmente são denominados agrotóxicos, defensivos agrícolas e/ou produtos fitossanitários. A 
OLIVEIRA, G.M. et al. Descarte responsável de embalagens de agrotóxico. PUBVET, Londrina, V. 7, N. 8, Ed. 231, Art. 1527, Abril, 2013.

falta de informação pelos usuários ocasionou um uso sem controle desses produtos que colocou em risco a saúde da população e dos animais, além de causar contaminação ambiental, incluindo solos, rios e atmosfera.

Para haver um maior controle, criaram-se manuais e outros meios de orientação a fim de instruir toda cadeia envolvida (usuários, fabricantes, comerciantes) no uso desses produtos e descarte responsável das embalagens vazias, com o objetivo de minimizar os efeitos negativos causados por esses produtos e embalagens. Além dessas medidas educativas, foram criadas leis específicas que regulamentam e fiscalizam a utilização destes produtos.

A destinação final de embalagens de agrotóxicos requer uma integração de todo o elo envolvido na fabricação, comercialização, utilização, licenciamento, fiscalização e monitoramento das atividades relacionadas com as mesmas. Devido à grande diversidade de formulações de agrotóxicos, existe uma Lei específica regulamentada, que objetiva prevenir os eventuais riscos de acidentes decorrentes da manipulação, manuseio, transporte e destino das embalagens de agrotóxicos, referente à saúde humana e à conservação do meio ambiente (SOUZA e FAVARO, 2007).

Neste contexto, o objetivo do presente trabalho é fazer uma revisão bibliográfica e conscientizar produtores rurais, pesquisadores e a população em geral, sobre a importância do descarte correto de embalagens vazias de agrotóxicos, a fim de minimizar os problemas que estes causam à sociedade. Visto que cada membro do elo da cadeia produtiva tem sua responsabilidade perante esse assunto, nota-se claramente a necessidade de informá-los e conscientizá-los sobre os procedimentos do descarte correto das embalagens vazias, que abrange desde a compra do produto até sua destinação final.

\section{REVISÃO BIBLIOGRÁFICA}

\section{Agrotóxicos}

Souza e Favaro (2007) relatam que nos anos 50 houve necessidade de adoção de novas tecnologias na agricultura, incluindo o uso de agrotóxicos por 
OLIVEIRA, G.M. et al. Descarte responsável de embalagens de agrotóxico. PUBVET, Londrina, V. 7, N. 8, Ed. 231, Art. 1527, Abril, 2013.

causa do aumento da produtividade agrícola em consequência do crescimento populacional. Esse contexto ficou conhecido como Revolução Verde, onde iniciou a intervenção de tecnologias na agricultura. Sendo que, antes deste período, há mais de dois mil anos atrás, já se fazia uso, de técnicas de proteção à colheita contra pragas.

Os agrotóxicos são constituídos por compostos químicos e biológicos utilizados para matar e proteger a colheita contra as pragas agrícolas. Os mesmos são classificados em: inseticidas, fungicidas e herbicidas. Sendo que, os inseticidas têm ação contra insetos, formigas e larvas, os fungicidas contra fungos e os herbicidas combatem ervas daninhas (OMS, 1997 apud PEROSSO e VICENTE, 2007).

No ano de 1975, foi instituído um plano econômico pelo governo brasileiro, denominado Plano Nacional de Desenvolvimento (PND) responsável pela abertura do Brasil ao comércio de agrotóxicos que estabeleceu que o agricultor deveria realizar a compra do veneno com recursos do crédito rural, determinando a inclusão de uma cota definida de agrotóxico para cada financiamento requerido pelo agricultor ao banco (OMS, 1997 apud PEROSSO e VICENTE, 2007 ).

Segundo a Organização Mundial de Saúde (1997) essa obrigatoriedade de compra de uma cota de agrotóxicos, somada à propaganda dos fabricantes, determinou um enorme desenvolvimento e propagação da utilização dos agrotóxicos no Brasil, que é atualmente um dos maiores consumidores mundiais, o que resulta em inúmeros problemas, tanto de saúde da população como de meio ambiente. Muito desses produtos não possuem antídotos e são proibidos em seus países de origem (PEROSSO e VICENTE, 2007).

Os agrotóxicos também podem ser classificados em relação à toxicidade, de acordo com a tabela abaixo: 
OLIVEIRA, G.M. et al. Descarte responsável de embalagens de agrotóxico. PUBVET, Londrina, V. 7, N. 8, Ed. 231, Art. 1527, Abril, 2013.

TABELA 1 - Classificação toxicológica dos agrotóxicos segundo a DL 50

\begin{tabular}{|c|c|c|}
\hline Grupos & Descrição & $\begin{array}{l}\text { Dose capaz de matar } \\
\text { um adulto }\end{array}$ \\
\hline $\begin{array}{l}\text { Extremamente } \\
\text { tóxicos }\end{array}$ & $\left(\mathrm{DL}_{50}<50 \mathrm{mg} / \mathrm{kg}\right.$ de peso vivo $)$ & $\begin{array}{l}\leq 5 \mathrm{mg} / \mathrm{kg}-\text { algumas } \\
\text { gotas }\end{array}$ \\
\hline Muito tóxicos & $\begin{array}{l}\left(\mathrm{DL}_{50}-50 \text { a } 500 \mathrm{mg} / \mathrm{kg} \text { de peso }\right. \\
\text { vivo })\end{array}$ & 1 colher de chá \\
\hline $\begin{array}{l}\text { Moderadamente } \\
\text { tóxicos }\end{array}$ & $\begin{array}{l}\left(\mathrm{DL}_{50}-500 \text { a } 5000 \mathrm{mg} / \mathrm{kg} \text { de }\right. \\
\text { peso vivo })\end{array}$ & 1 colher de sopa \\
\hline Pouco tóxicos & $\left(\mathrm{DL}_{50}>5000 \mathrm{mg} / \mathrm{kg}\right.$ de peso vivo $)$ & 2 colheres de sopa \\
\hline \multicolumn{3}{|c|}{ Fonte: TRAPÉ 1993 apud PEROSSO e VICENTE, 2007} \\
\hline \multicolumn{3}{|c|}{$\begin{array}{l}\text { A ANVISA (2011) classifica os agrotóxicos de acordo com o perigo à } \\
\text { saúde, o que é representado em quatro classes. Cada classe é representada } \\
\text { por uma cor no rótulo do produto, o que pode ser analisado na tabela a seguir: }\end{array}$} \\
\hline Classe & Toxicidade & $\begin{array}{l}\text { tificação no rótulo do } \\
\text { produto }\end{array}$ \\
\hline I & Extremamente Tóxicos & Cor vermelha \\
\hline II & Altamente Tóxicos & Cor amarela \\
\hline III & Moderadamente Tóxico & Cor azul \\
\hline IV & Pouco Tóxico & Cor verde \\
\hline
\end{tabular}

Fonte: ANVISA (2011)

\section{Embalagens de agrotóxicos}

As embalagens vazias de agrotóxicos são com certas frequências colocadas em locais impróprios, por isso, tornam-se perigosas para o homem, os animais e o meio-ambiente (solo, ar e água), quando descartadas incorretamente. Elas são fonte de contaminação de nascentes, córregos, rios e 
OLIVEIRA, G.M. et al. Descarte responsável de embalagens de agrotóxico. PUBVET, Londrina, V. 7, N. 8, Ed. 231, Art. 1527, Abril, 2013.

mananciais de água que abastecem tanto propriedades rurais, quanto as cidades. Além disso, algumas pessoas reutilizam embalagens para armazenar alimentos e ração de animais (INPEV, 2012).

A Associação dos Engenheiros Agrônomos do Estado de São Paulo (AEASP) divide as embalagens agrotóxicas em duas categorias: Embalagens Laváveis e Não Laváveis. As embalagens laváveis são caracterizadas como embalagens rígidas que possuem formulações líquidas para serem diluídas em água. Nessas embalagens deve ser realizada a tríplice- lavagem ou lavagem sob pressão. As embalagens não laváveis se referem a embalagens flexíveis e rígidas que não utilizam a água como veiculo de pulverização, devendo ser mantidas intactas adequadamente tampadas e sem vazamento. Essas embalagens não poderão ser recicladas por estarem contaminadas (SOUZA e FAVARO, 2007).

JUNIOR PHILIPPI e BARREIRA (2002) caracterizam os resíduos de embalagens de inseticidas e agrotóxicos como resíduos perigosos, pois os mesmos contêm substâncias químicas que podem modificar o ambiente nas suas mais diferentes formas de vida. Além disso, os mesmos interferem de forma definitiva na cadeia natural, contaminando o solo, a água e o ar e influenciando diretamente na saúde da população, seja ela de qualquer nível social.

\section{Transporte}

Segundo a Associação Nacional de Defesa Vegetal - ANDEF (2010), o transporte dos produtos fitossanitários deve ser realizado com muita responsabilidade, pois exige que diversas medidas sejam tomadas, tanto para a prevenção de risco de acidentes em vias urbanas, quanto para aumentar as chances de sucesso numa tarefa de atendimento de emergência. Tais medidas têm por objetivo a proteção da integridade física das pessoas, assim como preservação meio ambiente.

O agrotóxico deve ser transportado de maneira segura, devendo o condutor ser habilitado pelo SENAI (Serviço Nacional de Aprendizagem 
OLIVEIRA, G.M. et al. Descarte responsável de embalagens de agrotóxico. PUBVET, Londrina, V. 7, N. 8, Ed. 231, Art. 1527, Abril, 2013.

Industrial) ou SENAT (Serviço Nacional de Aprendizagem do Transporte) e possuir autorização. O veículo deve estar em boas condições cumprindo a legislação de transporte de produtos perigosos e sempre acompanhado da nota fiscal. O não cumprimento acarreta em multas para o vendedor e para quem transporta o produto. Todos os veículos que transportam produtos perigosos deverão estar equipados com o kit de emergência devendo estar em local de fácil acesso e em perfeitas condições de uso (ANDEF, 2010).

A Associação Nacional dos Distribuidores de Defensivos Agrícolas e Veterinários- ANDAV (2000) argumenta que no transporte, as embalagens laváveis devem estar acompanhadas de uma Declaração do Proprietário de que se encontram adequadamente lavadas de acordo com as recomendações da NBR 13.968. Na Declaração do Proprietário deverão constar os seguintes dados: Nome do Proprietário das Embalagens; Nome e Localização da Propriedade Rural; Quantidade e tipos de embalagens (plástico, vidro, metal ou caixa coletiva de papelão) e Data da entrega.

\section{Armazenamento}

Um dos fatores importantes a ser considerado no local de armazenamento de agrotóxicos, é a temperatura no interior do depósito. De acordo com a EMBRAPA (2007), temperaturas mais elevadas podem ocasionar o aumento da pressão interna nos frascos, o que pode provocar a ruptura da embalagem, ou mesmo, propiciar o risco de contaminação de pessoas durante seu manuseio. O risco aumenta, colocando em perigo a vida de pessoas e/ou animais, visto que também pode ocorrer a liberação de gases tóxicos, principalmente daquelas embalagens que não foram completamente esvaziadas, ou que foram contaminadas externamente por escorrimentos durante o uso. (PEROSSO e VICENTE, 2007)

Dessa forma a EMBRAPA (2003) recomenda de maneira geral, a armazenar os agrotóxicos em locais cobertos de modo a proteger os produtos contra diversidades climáticas. Com relação à infra-estrutura dos depósitos, sugere que a construção seja de alvenaria, devendo o piso ser revestido de 
OLIVEIRA, G.M. et al. Descarte responsável de embalagens de agrotóxico. PUBVET, Londrina, V. 7, N. 8, Ed. 231, Art. 1527, Abril, 2013.

material impermeável, liso e fácil de limpar. É necessário se atentar para possíveis infiltrações no local, pois acarreta em umidade, devendo ser evitadas. No local de armazenamento é necessária a instalação de equipamentos de proteção coletiva (EPC), como por exemplo, lava olhos e chuveiros para caso de acidentes. Deve ser mantido um controle efetivo em relação às datas de validade dos produtos.

De acordo com a Agência Nacional de Vigilância Sanitária - ANVISA (2011), o agrotóxico deve ser armazenado em local seco, longe de fontes de águas, rações, medicamentos e sementes. Dessa forma deve ser abrigado em local distante de habitação de animais e seres humanos, estar sobre estrados afastados da parede, não tocar no piso sendo este cimentado e sem rachaduras. Do mesmo modo, o local de armazenamento deve possuir boa ventilação.

\section{Aplicação}

A aplicação do produto deverá ser feita sempre por profissionais capacitados para este serviço e é necessária a utilização de Equipamentos de Proteção Individual (EPI). Deve ser realizada a favor das correntes de vento para evitar concentrações do produto. O tempo de contato com o produto deve ser o mínimo possível, pois, quanto menor o tempo de contato, consequentemente, menor os riscos de contaminação. Nunca dever ser realizada a aplicação do agrotóxico durante os períodos de chuva, pois isso acarreta poluição dos solos, rios, lagos e possível intoxicação dos animais, além de desperdício do produto, tempo e dinheiro (ANVISA, 2011).

\section{Problemas à Saúde Pública e Ambiental}

O agrotóxico é um produto tóxico, que representa ameaça a saúde dos animais e seres humanos, pois, pode causar intoxicação acompanhada de sinais clínicos como: dores de cabeça, tonteira, problemas respiratórios, cansaço, tosse, vômitos, entre outros. Quando a penetração do produto ocorre por via dérmica pode causar irritações e alergias na pele. Quando a intoxicação 
OLIVEIRA, G.M. et al. Descarte responsável de embalagens de agrotóxico. PUBVET, Londrina, V. 7, N. 8, Ed. 231, Art. 1527, Abril, 2013.

é mais grave pode ocorrer aumento da pressão arterial, dificuldades respiratórias e problemas neurológicos, como confusão mental e convulsões, que podem levar ao coma e até a morte (TREVISAN e ZAMBRONE, 2002 apud MINAMI, PASQUALETTO e LEITE, 2008).

As embalagens de agrotóxicos descartadas incorretamente provocam a contaminação das águas, através da infiltração de resíduos de agrotóxicos para lençóis freáticos, rios, córregos, lagos, dentre outros. Além disso, podem provocar a contaminação atmosférica, resultante da dispersão de partículas através do processo de pulverização ou da manipulação do processo de formulação e evaporação de produtos mal-estocados (MOREIRAet al 2002 apud SOUZA e FAVARO, 2007).

Tudo isso ocorre principalmente devido ao manejo inadequado, com aplicação de super dosagens, utilização de agrotóxico incorreto para certo tipo de lavoura, número de aplicações incorretas, etc.Todavia o maior problema está relacionado ao uso desordenado e ao descarte inadequado dado as embalagens que contem este produto.

\section{Descarte}

A destinação final das embalagens vazias de agrotóxicos é um procedimento complexo, que requer a participação efetiva de todos os agentes envolvidos na fabricação, comercialização, utilização, licenciamento, fiscalização e monitoramento das atividades relacionadas com o manuseio, transporte, armazenamento e processamento dessas embalagens (MINAMI, PASQUALETTO e LEITE, 2008).

As embalagens vazias de agrotóxicos sempre foram descartadas sem controle e fiscalização e a prática de enterrá-las, atualmente, é considerada inadequada devido aos altos riscos de contaminação do solo e das águas subterrâneas (JUNIOR PHILIPPI e BARREIRA, 2002).

De acordo com a Associação Nacional de Distribuidores de Defensivos Agrícolas (ANDAV) o principal motivo para a destinação final correta para as embalagens vazias dos agrotóxicos é diminuir o risco para a saúde das pessoas 
OLIVEIRA, G.M. et al. Descarte responsável de embalagens de agrotóxico. PUBVET, Londrina, V. 7, N. 8, Ed. 231, Art. 1527, Abril, 2013.

e de contaminação do meio ambiente. Durante vários anos, o Governo vem trabalhando em conjunto com a iniciativa privada num programa nacional para o destino final das embalagens, e hoje se sabe que os principais ensinamentos sobre o tema abordado têm surgido através de iniciativas da indústria e da participação voluntária da sociedade (PEROSSO e VICENTE, 2007).

\section{INPEV}

O INPEV (Instituto Nacional de Processamento de Embalagens Vazias) é uma entidade sem fins lucrativos que representa a indústria fabricante de defensivos agrícolas em sua responsabilidade de destinar corretamente as embalagens devolvidas pelos agricultores. Foi criado a partir de uma iniciativa da indústria, para atender às responsabilidades sociais e ambientais (INPEV, 2012).

O INPEV possui atualmente 94 empresas e 10 entidades do setor como associados. Essas empresas contribuem financeiramente com o instituto, participam de cargos eletivos e de Assembléias Gerais e também possuem direito a voto. As entidades associadas participam das Assembléias Gerais sem direito a voto e não pagam contribuição ao instituto. (INPEV, 2012).

O Instituto é responsável por transportar adequadamente as embalagens devolvidas de Postos para Centrais e das Centrais de Recebimento para destino final (Recicladoras ou incineradoras) conforme é determinado pela Lei 9.974 / 2000 e Decreto 4.074 / 2002. Para administrar o processo logístico, utiliza o conceito de logística reversa, na qual disponibiliza o caminhão que transporta os agrotóxicos (embalagens cheias) para os distribuidores e cooperativas do setor e que voltariam descarregados, trazendo as embalagens vazias (a granel ou compactadas) armazenadas nas unidades de recebimento (PEROSSO e VICENTE, 2007).

\section{Legislação}

Diante do contexto do descarte incorreto das embalagens de agrotóxicos que ocasiona problemas ambientais, a saúde humana e animal houve a 
OLIVEIRA, G.M. et al. Descarte responsável de embalagens de agrotóxico. PUBVET, Londrina, V. 7, N. 8, Ed. 231, Art. 1527, Abril, 2013.

necessidade da criação de leis para fiscalizar a utilização de agrotóxicos. Em 2000 foi estabelecida a lei federal n 9.974 que "dispõe sobre pesquisa, a experimentação, a produção, a embalagem e rotulagem, o transporte, o armazenamento, a comercialização, a propaganda comercial, a utilização, a importação, a fiscalização de agrotóxicos, seus componentes e afins" (DIÁRIO OFICIAL, 2000 apud JUNIOR e BARREIRA, 2002).

O descumprimento da lei é considerado crime ambiental, sujeito a multa para o agricultor, comerciantee para o fabricante e pena de reclusão de 2 a 4 anos. Essa lei disciplina a destinação final de embalagens vazias de agrotóxicos determinando responsabilidades para o agricultor, o canal de distribuição, o fabricante e o poder público (PEROSSO e VICENTE, 2007).

O cumprimento das leis ambientais é insuficiente para as empresas que desejam ampliar suas atividades. Recentemente, o mercado vem exigindo das instituições mais ações em prol do meio ambiente, demanda não apenas a preocupação econômica, mas também os balanços sociais. Diante dessa realidade, a responsabilidade sócio-ambiental tornou-se indispensável para as organizações promoverem projetos que inviabilizam a melhoria na qualidade de vida da comunidade e que reduzam o impacto sobre o meio ambiente (CBIC 2006 apud SOUZA e FAVARO, 2007).

Essas empresas têm por meta alcançar o melhor âmbito global em produtos, preocupando-se com o meio ambiente, preservando a natureza e criando valores. Porém, de forma geral, falta muito para que se possa conscientizar a população de que o meio ambiente deve ser conservado, sendo que, muito se explora e pouco se conserva (SOUZA e FAVARO, 2007).

\section{Responsabilidades}

A Lei 9.974/00 regulamenta que as obrigações quanto ao descarte de embalagens vazias de agrotóxicos se aplica a todos os elos que constituem a cadeia agropecuária, sendo eles, agricultores, comerciantes, fabricantes e o poder público (JUNIOR PHILIPPI e BARREIRA, 2002). 
OLIVEIRA, G.M. et al. Descarte responsável de embalagens de agrotóxico. PUBVET, Londrina, V. 7, N. 8, Ed. 231, Art. 1527, Abril, 2013.

Para realizar a compra de um produto agrotóxico é necessário realizar uma avaliação correta dos problemas da lavoura como, ataque de pragas, doenças e plantas daninhas. Essa medida é de inteira responsabilidade do engenheiro agrônomo que deve emitir um receituário (ANVISA, 2011).

\section{a) Responsabilidades do usuário}

JUNIOR PHILIPPI e BARREIRA (2002) indicam que é de responsabilidade dos usuários devolverem as embalagens vazias dos produtos adquiridos aos próprios comerciantes que possuam instalações adequadas ou em postos de recebimento. As embalagens devem ser devolvidas dentro do período de um ano, neste intervalo os usuários devem armazená-las de forma adequada em sua propriedade, em local abrigado de chuva, que seja ventilado e separado de alimentos ou rações, como fazem com os produtos (embalagens cheias), tomando o cuidado para guardar as notas fiscais de compra e comprovantes de devolução.

É de responsabilidade do usuário, transportar as embalagens, devendo acumulá-las, dentro do prazo estabelecido, ao máximo que possa justificar o custo do transporte até a central de recebimento. Se, após esse prazo, o produto permanecer na embalagem, é permitido sua devolução em até seis meses, após o término do prazo legal de validade (SOUZA e FAVARO, 2007)

Cabe ainda aos usuários, realizar corretamente uma lavagem especial das embalagens rígidas (plásticas, metálicas ou de vidro) que acondicionam formulações para serem diluídas em água, de acordo com a NBR 13.968 da ABNT - Associação Brasileira de Normas Técnicas (JUNIOR PHILIPPI e BARREIRA, 2002).

Ressalta-se que $61 \%$ das embalagens devolvidas contêm resíduos e que o descarte inadequado das embalagens de agrotóxicos em rios, nas plantações e também em aterros, provoca graves problemas de poluição ambiental.(SUGIMOTO, 2005 apud SOUZA e FAVARO, 2007)

Para diminuir a incidência de resíduos nas embalagens de agrotóxicos deve ser realizada a tríplice-lavagem, que promove mais segurança para todas 
OLIVEIRA, G.M. et al. Descarte responsável de embalagens de agrotóxico. PUBVET, Londrina, V. 7, N. 8, Ed. 231, Art. 1527, Abril, 2013.

as pessoas que manuseiam as embalagens vazias até a destinação final. Este procedimento também se torna importante para os animais e o meio ambiente, protegendo-os dos riscos que representam as embalagens contaminadas, abandonadas nos campos, pastos, lavouras e rios. Portanto, tomando estes cuidados todos são beneficiados, uma vez que o agricultor faz economia, tendo o maior aproveitamento possível do conteúdo das embalagens de um produto que representa um alto custo. Do mesmo modo, o meio ambiente não corre risco de contaminação, aumentando significativamente a segurança no processo (FERRAZ, 2006 apud SOUZA e FAVARO, 2007).

Junior e Barreira (2002) afirmam que esse procedimento denominado por tríplice-lavagem pode ser descrito da seguinte forma:

1. Esvaziar completamente o conteúdo da embalagem no tanque do pulverizador;

2. Adicionar água limpa à embalagem até $1 / 4$ do seu volume;

3. Tampar bem a embalagem e agitá-la por aproximadamente 30 segundos;

4. Despejar a água de lavagem no tanque do pulverizador.

5. Repetir o mesmo procedimento mais duas vezes;

6. Após a lavagem, tampar e perfurar ou inutilizar a embalagem de forma a impedir a reutilização.

7. É importante para facilitar a identificação dos produtos, que o rótulo seja mantido intacto.

De acordo com a ANDEF (2010) outro método para proceder à lavagem é a lavagem sob pressão que consiste num sistema de lavagem integrado ao pulverizador. Este equipamento utiliza a própria bomba do pulverizador para gerar a pressão para o bico de lavagem. A água limpa utilizada para lavagem das embalagens é captada pela própria bomba do pulverizador de um tanque extra que pode ou não estar integrado ao equipamento. 
OLIVEIRA, G.M. et al. Descarte responsável de embalagens de agrotóxico. PUBVET, Londrina, V. 7, N. 8, Ed. 231, Art. 1527, Abril, 2013.

O INPEV (2012) descreve a lavagem sob pressão da seguinte maneira:

1. Transferência do conteúdo da embalagem para o tanque do pulverizador; deve-se emborcar a embalagem pressionando o bocal sobre o bico rotativo para abertura da válvula;

2. Manter a embalagem assim por pelo menos 30 segundos;

3. Retirar a pressão sobre a embalagem, mantendo-a nessa posição até o completo esgotamento da mesma.

Assim como na tríplice-lavagem, neste caso, também deverão ser perfurados todos os fundos das embalagens plásticas e metálicas para que as mesmas não sejam reutilizadas. É indispensável o uso de equipamentos de proteção individual em todo processo de manipulação com material ou produto tóxico.

\section{b) Responsabilidades do comerciante}

Aos comerciantes cabe a responsabilidade de adequar suas instalações, construir postos de recebimento ou planejar formas a facilitar a devolução das embalagens por parte dos usuários, indicando na nota fiscal o local de devolução das embalagens vazias, além de orientá-los sobre o procedimento correto no manejo das embalagens (JUNIOR PHILIPPI e BARREIRA, 2002).

\section{Postos de Recebimento}

Foram criados postos de recebimento que são construções menores, gerenciadas por uma associação de distribuidores e que têm como função receber, inspecionar e classificar as embalagens entre lavadas e não-lavadas e emitir recibos confirmando a entrega e encaminhar as embalagens até as centrais de recebimento (INPEV, 2012).

Estas unidades de recebimento contaram com o investimento da indústria para acelerar o processo de sua implantação local. Desse modo, a indústria contribuiu em processos de aperfeiçoamento, acompanhando a implantação das unidades de recebimento e criando um programa de 
OLIVEIRA, G.M. et al. Descarte responsável de embalagens de agrotóxico. PUBVET, Londrina, V. 7, N. 8, Ed. 231, Art. 1527, Abril, 2013.

educação, treinamento e conscientização voltado para a instrução dos usuários, do sistema de distribuição e operadores das unidades de recebimento. Além disso, disponibilizou gratuitamente cursos de qualificação no site do INPEV (SOUZA e FAVARO, 2007). A ANDAV (2000) sugere para que o processo se torne mais viável haja parceria entre revendedores para implantação e gerenciamento de Postos de Recebimento de Embalagens.

\section{c) Responsabilidades do fabricante}

É dever dos fabricantes a destinação final das embalagens e/ou aos produtos devolvidos pelo usuário.

Segundo a ANDAV (2000), os fabricantes devem:

1. Prover o recebimento, a reciclagem ou a destruição das embalagens vazias devolvidas às unidades de recebimento em, no máximo, um ano, a contar da data de devolução pelos usuários/agricultores;

2. Informar os comerciantes sobre os locais onde estão localizadas as Centrais de Recebimento de embalagens para as operações de prensagem e redução de volume;

3. Elaborar, junto ao Poder Público, programas educativos e mecanismos de controle e conscientização sobre a lavagem (Tríplice e sob Pressão) e à devolução das embalagens vazias por parte dos usuários;

4. Desenvolver, em colaboração com o Poder Público, medidas que orientem os usuários em relação ao atendimento das exigências previstas no Decreto n. ${ }^{\circ} 3550$, enquanto se realizam as adequações dos estabelecimentos comerciais e dos rótulos e bulas;

5. Modificar os modelos de rótulos e bulas para que contenham informações sobre os procedimentos de lavagem, armazenamento, transporte, devolução e destinação final das embalagens vazias.

\section{Centrais de recebimento}

Segundo o INPEV (2012) as centrais, são unidades maiores de recebimento de embalagens vazias de agrotóxicos, tendo no mínimo $160 \mathrm{~m}^{2}$ 
OLIVEIRA, G.M. et al. Descarte responsável de embalagens de agrotóxico. PUBVET, Londrina, V. 7, N. 8, Ed. 231, Art. 1527, Abril, 2013.

de construção. Possuem licenciamento ambiental e são coordenadas por uma associação de distribuidores/cooperativas com o co-gerenciamento do INPEV. Sendo responsáveis por realizar os seguintes serviços:

1. Receber de agricultores e unidades de recebimento, embalagens de agrotóxicos;

2. Inspecionar e classificar as embalagens entre laváveis e não-laváveis;

3. Emitir recibos para confirmação da entrega das embalagens;

4. Separar as embalagens por tipo, sendo eles, PET, COEX, PEAD, MONO, entre outros;

5. Compactar as embalagens de acordo com cada tipo de material;

6. Emitir uma ordem para que o INPEV se encarregue do transporte para o destino final das embalagens

Após a chegada na central de recebimento, as embalagens são destinadas a uma unidade de beneficiamento, que realiza um processo de reciclagem mecânica a qual consiste em moagem, lavagem, centrifugação e extrusão, posteriormente são separadas manualmente das resinas plásticas. 0 plástico recebido é classificado e selecionado em relação ao tipo de matériaprima e quanto à cor da resina plástica, antes de ser triturado e lavado, para a remoção de impurezas sejam elas papel, terra, sujeira ou resíduos. Após os processos de moagem e lavagem, as lascas do material triturado são ensacadas e levadas para a centrífuga para receber completa desidratação dos fragmentos plásticos (AEASP 1998 apud SOUZA e FAVARO, 2007).

\section{Reciclagem}

Reciclar é revalorizar os descartes domésticos e industriais mediante diversas operações, permitindo que os materiais sejam reutilizados como matéria-prima para outros produtos (DOMINGUESet al, 2006 apud MINAMI, PASQUALETTO e LEITE, 2008). Essa atividade se desenvolve de maneira conjunta com fatores sociais, econômicos e ambientais (SOUZA e FAVARO, 2007). A reciclagem visa solucionar o crítico problema ambiental causado pelo 
OLIVEIRA, G.M. et al. Descarte responsável de embalagens de agrotóxico. PUBVET, Londrina, V. 7, N. 8, Ed. 231, Art. 1527, Abril, 2013.

acúmulo de embalagens nas propriedades rurais, que aumenta a cada ano, e que por muitas vezes, não possui nenhuma proposta de solução definitiva (PASQUALETTO ET AL 2004 apud MINAMI, PASQUALETTO e LEITE, 2008).

As embalagens vazias de agrotóxicos sejam elas de vidro, metal ou plástico podem ser recicladas. Sendo assim, o processo de reciclagem nos Postos de Recebimento do sistema de destinação final de embalagens vazias de agrotóxicos inicia-se, com um inspecionamento rigoroso das embalagens e classificação entre lavadas e não lavadas. Para haver a reciclagem as embalagens devem ser corretamente lavadas, para não causar impactos nos efluentes das indústrias que farão o processo. Depois de separadas, as embalagens lavadas são transformadas através do processo de compactação em fardos, de acordo com o tipo de plástico e quanto à cor, para que sejam enviadas a seu destino final, ou seja, à reciclagem. E as embalagens nãolavadas são separadas das demais. As não-laváveis e as que não foram devidamente lavadas através do método de tríplice-lavagem são encaminhadas para incineração. As laváveis são constituídas de quatro tipos de materiais: PEAD MONO, COEX, PET e Metálica. De acordo com cada tipo de substância plástica ou metálica utilizada na composição das embalagens, poderá ser determinado o material que será produzido através da reciclagem. Cada tipo de embalagem é identificado por siglas e uma numeração específica, sendo estes padrões adotados mundialmente (INPEV, 2012).

Segundo o INPEV (2012) dentre as embalagens vazias de agrotóxicos, $95 \%$ podem ser encaminhadas para reciclagem, os outros $5 \%$ restantes são encaminhados para incineração. As incineradas são as embalagens não laváveis, e as embalagens que não foram devidamente tríplice-lavadas pelos agricultores.

As embalagens de vidro, assim como as de plástico, também devem ser tríplice-lavadas e trituradas nas Centrais de Recebimento, antes de serem transportadas para as indústrias vidreiras. Nessas indústrias, as vidrarias serão aquecidas e derretidas a temperaturas acima de $1300^{\circ} \mathrm{C}$, sendo essa temperatura eficiente para degradar as moléculas dos princípios ativos e 
OLIVEIRA, G.M. et al. Descarte responsável de embalagens de agrotóxico. PUBVET, Londrina, V. 7, N. 8, Ed. 231, Art. 1527, Abril, 2013.

solventes das formulações de agrotóxicos. Devem ser considerados alguns pontos básicos antes do envio para a indústria vidreira, sendo eles a separação dos vidros por cor (âmbar, verde e branco), e cuidando para evitar misturas e contaminantes como, areia, pedra e terra. As tampas plásticas e as alças de metal devem ser retiradas antes das embalagens serem trituradas (SOUZA e FAVARO, 2007).

Por motivos de segurança, facilidade no manuseio e maior resistência no transporte, observaram-se que as embalagens de plástico eram as favoritas dos usuários de defensivos agrícolas. Com a publicação da Lei 7.802 de 11/07/89 e do Decreto 98.816 de 11/01/90, foi estabelecido que só seria aceito o uso das embalagens de vidro nos casos extremos onde não poderiam ser utilizadas as embalagens plásticas (ARAÚJO 1997 apud SOUZA e FAVARO, 2007).

Perosso e Vicente (2007) em seus trabalhos compartilhavam a ideia com Souza e Favaro (2007) a respeito dos utensílios produzidos por meio da reciclagem das embalagens vazias sendo eles: conduíte corrugado, cruzeta de poste de transmissão de energia, corda de PEAD MONO, corda de PET, vergalhões de aço, madeira plástica, embalagens para óleo lubrificante, dutos corrugados, tubo para esgoto, tampas para embalagens de defensivos agrícolas, luvas para emenda, economizadores de concreto, barricas de papelão, barrica plástica para incineração, caixa de bateria automotiva, sacos plásticos para lixo hospitalar, bombona plástica, caixa para fiação elétrica. (INPEV no. 2,1 2004). Essas tampas das embalagens de defensivos agrícolas representam o primeiro produto que retorna para seu uso original por meio da reciclagem.

Os produtos finais da reciclagem são reutilizados de diversas maneiras, como exemplo, o conduíte que é $100 \%$ reciclado, sendo o primeiro produto a ser produzido a partir da reciclagem das embalagens vazias de agrotóxico. A empresa que fabrica saco plástico para armazenamento de lixo hospitalar, também é responsável pelo fornecimento do conduíte (SOUZA e FAVARO, 2007). 
OLIVEIRA, G.M. et al. Descarte responsável de embalagens de agrotóxico. PUBVET, Londrina, V. 7, N. 8, Ed. 231, Art. 1527, Abril, 2013.

A madeira plástica é totalmente reciclada, sendo utilizado como mourões de cerca, deck de piscina, bancos e batentes de portas, substituindo integralmente a madeira natural. Na construção civil já se faz uso do economizador de concreto que substitui o isopor no enchimento de lajes, o que promove uma economia de $30 \%$ de concreto e $50 \%$ de aço da construção, além de proporcionar estruturas mais leves (INPEV, 2012).

\section{d) Responsabilidades do Poder Público}

É dever do Poder Público, segundo o INPEV (2012), a responsabilidade sobre o descarte correto:

1. Inspecionar o funcionamento do sistema de destinação final de embalagens de defensivos agrícolas;

2. Licenciar o funcionamento para postos de recebimento de acordo com os órgãos competentes de cada estado;

3. Educar, conscientizar e apoiar o agricultor, quanto as suas responsabilidades dentro do processo.

\section{Incineração}

O sistema de incineração das embalagens contaminadas de agrotóxicos só pode ser realizado pelas empresas autorizadas pelo INPEV, tendo estas, licenciamento ambiental, concedido por órgãos ambientais competentes. As incineradoras transformam as embalagens contaminadas em cinzas inertes e gases de natureza conhecida e ambientalmente aceitável. (MINAMI, PASQUALETTO e LEITE, 2008).

O único objetivo do processo de incineração é eliminar os resíduos sólidos ou líquidos. A incineração só pode ser realizada de forma totalmente segura, em instalações apropriadas e legalizadas, que estejam em ótimas condições de fazer a combustão controlada (ARAÚjO 1997 apud SOUZA e FAVARO, 2007). Quando o agricultor não tem viabilidade para o transporte na entrega de todo seu lixo à central de recebimento, ele próprio pode incinerar alguns tipos de embalagens combustíveis não-contaminadas, ou seja, aquelas 
OLIVEIRA, G.M. et al. Descarte responsável de embalagens de agrotóxico. PUBVET, Londrina, V. 7, N. 8, Ed. 231, Art. 1527, Abril, 2013.

que não entram em contato direto com as formulações que por elas são acondicionadas, esse processo pode ocorrer em fornos industriais na zona rural (SOUZA e FAVARO, 2007).

Todas as embalagens não-laváveis e as contaminadas devem ser incineradas. Um tipo de incineração é a Dedicada, pois permite uma maior abrangência no tipo de resíduos que são utilizados pelas cimenteiras. Esse tipo de incineração baseia-se no tratamento térmico de resíduos, utilizando ou não recuperação da energia térmica gerada pela combustão. Nas cimenteiras não podem ser utilizados resíduos com altos níveis de cloro e mercúrio, pois causam problema no processo de fabricação do clínquer- material resultante de reações de alta temperatura, envolvendo a matéria-prima do cimento (FEUP, 2006 apud SOUZA e FAVARO, 2007).

\section{Trituração}

O processo de trituração é composto por uma unidade trituradora móvel, criada com o objetivo de funcionar com maior agilidade, diminuindo o gargalo dos postos de recebimento e reduzindo os custos com frete. Sendo que, nesse estágio (triturado), do processo não existe mais o risco de contaminação, devido à baixa rotatividade do triturador, sendo possível impedir que se forme e se disperse qualquer quantidade de partículas de material contaminado. Segundo o informativo do INPEV No 25 (2005) esse processo foi adotado no Paraná desenvolvido pelo setor tecnológico do INPEV (SOUZA e FAVARO, 2007).

O processo de trituração promove economia de caminhões para o transporte, e o meio ambiente também é preservado, pois ocorre diminuição da emissão de gases na atmosfera, em uma quantidade importante, minimizando cerca de três vezes a quantidade que seria lançada pelos escapamentos dos caminhões, utilizada para o transporte das embalagens (inteiras) até que estas cheguem a sua destinação final. $O$ espaço de 
OLIVEIRA, G.M. et al. Descarte responsável de embalagens de agrotóxico. PUBVET, Londrina, V. 7, N. 8, Ed. 231, Art. 1527, Abril, 2013.

armazenagem das embalagens trituradas é beneficiado com o implante desse sistema (INPEV, 2012).

\section{Descarte correto no Brasil}

No Brasil há um consumo de cerca de $50 \%$ da quantidade de defensivos agrícolas utilizados na América Latina, e que envolve um comércio estimado em cerca de US\$2,56 bilhões com compras destes produtos (SINDAG, 2006). Com isso, ocupa o segundo lugar no consumo de produtos fitossanitários agrícolas, ficando atrás somente dos Estados Unidos da América (AGROLINK, 2006).

Algo que era visto frequentemente na zona rural começa a desaparecer, pois não se observa mais donas-de-casa utilizando baldes de veneno em tarefas cotidianas. No entanto, todos os integrantes do elo da cadeia produtiva agrícola, contribuem com sua parte neste processo. Os custos mais importantes neste sistema são os referentes à infra-estrutura- postos de recebimento, à logística e ao descarte das embalagens. Neste processo são investidos $R \$ 60,2$ milhões pela indústria fabricante de agrotóxicos, e $R \$ 10$ milhões pelo sistema de comercialização- distribuidores e cooperativas (SOUZA e FAVARO, 2007).

A primeira cidade, no Brasil, onde foi implantado o primeiro projeto de destinação de embalagens vazias de agrotóxicos, visando à sustentabilidade e a conscientização dos agricultores foi em Guariba (SP), no ano de 1993, coordenado pela ANDEF e pelo SINDAG (Sindicato Nacional da Indústria de Produtos para Defesa Agrícola), juntamente com entidades parceiras. Até 2001 foram ativadas 45 unidades de recebimento, na qual atingiu o seu ponto máximo no ano de 2002, com a criação do INPEV. Nos últimos seis anos, foram empregados mais de $\mathrm{R} \$ 270$ milhões no sistema. Até setembro de 2008, o INPEV atingiu a estimativa de mais de 100 mil toneladas, ou seja, 90\% de embalagens processadas, o que representa um recorde mundial, sendo que na Alemanha, o índice é $65 \%$, na França 50\%, no Japão 50\% e os Estados Unidos contribuem apenas com 20\% (ANDEF, 2012). 
OLIVEIRA, G.M. et al. Descarte responsável de embalagens de agrotóxico. PUBVET, Londrina, V. 7, N. 8, Ed. 231, Art. 1527, Abril, 2013.

Segundo dado do INPEV (2006) recentemente foi atingido à marca, de aproximadamente $94 \%$ das embalagens de agrotóxicos colocadas no mercado foram devolvidas para a indústria e tiveram destinação final correta. Contudo, empresas de vários setores argumentavam que criar um sistema para recolher embalagens aumentaria os custos para as empresas, e esse aumento seria repassado ao consumidor.

Alguns estados do Brasil como, o Paraná, Mato Grosso, São Paulo e Goiás são responsáveis pelas maiores taxas de devolução do país. No ano de 2011, somente no Paraná foram devolvidas pelos agricultores cerca de 4.490 toneladas. Já o estado do Mato Grosso devolveu aproximadamente 8.785 toneladas e São Paulo destinou cerca de 3.740 toneladas de embalagens vazias de agrotóxicos (INPEV, 2012).

\section{Considerações finais}

Com tudo que foi apresentado, nota-se claramente a importância do descarte responsável das embalagens vazias de agrotóxicos, com o intuito de minimizar os efeitos na saúde pública e os impactos ambientais provocados pelos resíduos de agrotóxicos contidos nessas embalagens. Para que isso ocorra, há necessidade de participação de todos os constituintes dos elos da cadeia agropecuária, sendo eles os usuários (agricultores), os comerciantes (canais de distribuição), os fabricantes (indústria) e o poder público.

\section{Referências Bibliográficas}

AGROLINK. Brasil registra avanço no controle de agrotóxicos. 2006. Disponível em:< http://www.agrolink.com.br>. Acesso em: 02 jun. 2012.

ASSOCIAÇÃO NACIONAL DE VIGILÂNCIA SANITÁRIA - ANVISA, 2011. Disponível em:<http://portal.anvisa.gov.br/wps/portal/anvisa/home>. Acesso em: 30 de mai. de 2012.

ASSOCIAÇÃO NACIONAL DE DEFESA VEGETAL - ANDEF. Manual de Transporte de Produtos Fitossanitários Manual de Transporte de Produtos Fitossanitários,2010, p.48. Disponível em: < http://www.andef.com.br/manuais/arquivos/ManualTransporte.pdf>. Acesso em: 30 mai. 2012. 
ASSOCIAÇÃO NACIONAL DE DEFESA VEGETAL - ANDEF. Manual de uso correto e seguro de produtos fitossanitários agrotóxicos, 2010, 28 p. Disponível em:

<http://www.andef.com.br/manuais/arquivos/ManualUCS.pdf>. Acesso em: 30 mai. 2012.

ASSOCIAÇÃO NACIONAL DOS DISTRIBUIDORES DE DEFENSIVOS AGRÍCOLAS E VETERINÁRIOS- ANDAV. Destinação Final de Embalagens Vazias deAgrotóxicos, 2000. Disponível em: <http://www.andav.com.br/repositorio/36.pdf>. Acesso em: 30 mai. 2012.

CARTILHA AGÊNCIA NACIONAL DE VIGILÂNCIA SANITÁRIA - ANVISA. Cartilha sobre Agrotóxicos: Série Trilhas do Campo, 2011, p.26. Disponível em: <http://portal.anvisa.gov.br/wps/wcm/connect/9e0b790048bc49b0a4f2af9a6e94f0d0/Cartilha. pdf?MOD=AJPERES $>$. Acesso em: 30 mai. 2012.

EMBRAPA 2003. Cultivo da Mandioca na Região Centro Sul do Brasil. 2003. Disponível em: <http://sistemasdeproducao.cnptia.embrapa.br/FontesHTML/Mandioca/mandioca_centrosu l/agrotoxicos.htm>. Acesso em: 30 mai. 2012.

INSTITUTO NACIONAL DE PROCESSAMENTO DE EMBALAGENS VAZIAS- INPEV. Destino das Embalagens. 2012. Disponível em:

<http://www.inpev.org.br/destino_embalagens/unidades_recebimento/unidades_recebimento. asp>. Acesso em: 01 jun. 2012.

JUNIOR PHILIPPI, A. P; BARREIRA, L. P. A problemática dos resíduos de embalagens de agrotóxicos no Brasil. Disponível em: <http://www.bvsde.paho.org/bvsaidis/mexico26/iv001.pdf>. Acesso em: 30 mai. 2012.

MINAMI, M. Y. M; PASQUALETTO, A. LEITE, J. F. Destinação Final de Embalagens Plásticas de Agrotóxicos no Estado de Goiás. 2008. 29 f. Tese (Trabalho de Conclusão de Curso de Engenharia Ambiental) - Departamento de Engenharia, Universidade Católica de Goiás, Goiânia, 2008. Disponível em:

<http://professor.ucg.br/SiteDocente/admin/arquivosUpload/7074/material/DESTINA\%C3\%87 \%C3\%830\%20FINAL\%20DE\%20EMBALAGENS\%20PL\%C3\%81STICAS\%20DE\%20AGROT\%C3 $\% 93 X I C O S p d f>$. Acesso em: 01 jun. 2012.

PEROSSO, B. G; VICENTE, G. P. Destinação Final de Embalagens de Agrotóxicos e seus Possíveis Impactos Ambientais. 2007. 95f. Tese (Trabalho de Conclusão de Curso de Engenharia Civil) - Fundação Educacional de Barretos, Faculdades Unificadas da Fundação Educacional de Barretos, 2007. Disponível em:

http://www.feb.br/cursos_engcivsc/TCCDestinacaoFinalEmbalagensAgrotoxicosPossiveisImpact osAmbientais.pdf >. Acesso em: 30 mai. 2012.

SINDICATO NACIONAL DA INDÚSTRIA DE PRODUTOS PARA DEFESA AGRÍCOLA- SINDAG.

Agrotóxico Ilegal dá Cadeia. Disponível em: < http://www.sindag.com.br/>. Acesso em: 02 jun. 2012.

SOUZA, C. R; FAVARO, J. L. Questionamentos Sobre a Destinação Final de Embalagens Vazias de Agrotóxicos, Revista Eletrônica Lato Sensu - UNICENTRO. n. 1, Ano 2, 2007. Disponível em: <

http://web03.unicentro.br/especializacao/Revista_Pos/P\%C3\%A1ginas/2\%20Edi\%C3\%A7\%C3 \%A3o/Aplicadas/PDF/25-Ed2_CS-Questio.pdf>. Acesso em: 30 mai. 2012. 